\title{
Injury control strategies: extending the quality and quantity of data relating to road traffic accidents in children
}

\author{
Ralph Henson, Judith M Hadfield, Sarah Cooper
}

\begin{abstract}
This review describes how an extended database of information can provide the opportunity to go beyond the traditionally distinct health, engineering, and education initiatives in order to identify the effectiveness of more overarching policies for injury control. Such information can be used to raise awareness and to encourage community participation in designing a road traffic accident prevention strategy.

$(\mathcal{A}$ Accid Emerg Med 1999;16:87-90)
\end{abstract}

Keywords: injury control; road traffic accidents; children; data linkage

The number of road deaths and reported serious injuries occurring on Britain's roads is declining. ${ }^{1}$ This, coupled with reductions in hospital case fatality in children and young adults, ${ }^{2}$ has made an important contribution to reaching the Health of the Nation target to reduce the death rate for accidents among children under 15 by at least $33 \%$ by 2005 . However, there is no cause for complacency. The UK death rates for child pedestrians are the second highest in Europe. ${ }^{3}$

Road safety effort continues to be directed towards accident prevention. This can be considered as having three key elements:

- Exposure control

- Environmental change

- Behaviour modification

A fourth element, improving "post-impact" care, has the potential to reduce further the morbidity and mortality associated with road traffic accidents. There is increasing evidence to show that improvements in medical care have been responsible for a recent fall in mortality ${ }^{2}$ and that further reductions are possible.

The lack of valid and complete data on children who have had a road traffic accident is a considerable obstacle to effective monitoring of these strategies. Existing information sources are fragmented across a range of agencies each focusing on different details and using different definitions of the same phenomena. Data are often not comparable, can be conflicting, and there are gaps in the information available. ${ }^{4}$ Furthermore, the growing recognition of the complex interaction of many underlying social factors and geographical inequalities in accident causation has also limited planning and evaluation.

There is great potential for developing epidemiological research in this field which can then provide the evidence on which to base recommendations for changes in practice. The com-
Errors arising from police statistics

- Precipitating factors may be underestimated

- Accidents involving vulnerable road users show highest levels of under-reporting

- Priorities for action may not be identified correctly

- Injuries may be missed or wrongly documented

mon consensus is that a multidisciplinary approach, using collaborative working between agencies responsible for health, road safety, education, and engineering is likely to be most effective. ${ }^{5-7}$

\section{Current information sources}

POLICE ROAD TRAFFIC ACCIDENT STATISTICS

The routine source of accident data, providing the basis for assessment of accident trends and the prioritisation and identification of remedial measures for traffic engineers, is the police reporting system (STATS 19). While this is generally accepted as being a valuable data source, it is flawed for two reasons. Not all road traffic accidents are reported to the police, and for those which are, there are inaccuracies. STATS 19 is perceived as a legal rather than a medical document with the main emphasis on environmental issues. There are no systems of audit to alert police officers to the importance of medical data or to measure the completeness of data collection.

Studies which considered the extent of under-reporting in the UK and in other countries were reviewed by James. ${ }^{8}$ Levels of reporting were defined as low for children, pedal cyclists, motorcyclists (especially those involved in single vehicle accidents), accidents occurring off road and in driveways, and those resulting in only minor injury. Underrepresentation of these groups may have led to their relative priority for action being reduced.

INFORMATION FROM EMERGENCY DEPARTMENTS Police reports have been criticised for failing to adequately depict the accident related injury. If health data were to be incorporated, a more comprehensive and precise picture of what is happening to children injured in road traffic accidents can be built up. In particular, data from hospital emergency departments represent a potentially important source of crash injury information and injury scoring systems are increasingly used to underpin such work. ${ }^{910}$ Hopkin's study using police road accident data enhanced with hospital information gives 
Table 1 Part of the draft national contract ${ }^{15}$

\begin{tabular}{llll}
\hline $\begin{array}{l}\text { A national contract on } \\
\text { accidents }\end{array}$ & Government and national players can: & Local players and communities can: & People can: \\
\hline Social and economic & $\begin{array}{c}\text { Improve areas of deprivation through } \\
\text { urban regeneration } \\
\text { Improve safety of roads }\end{array}$ & $\begin{array}{c}\text { Tackle social exclusion and joblessness } \\
\text { in the community } \\
\text { Improve facilities for pedestrians and } \\
\text { cycle paths }\end{array}$ & $\begin{array}{c}\text { Take opportunities to combat poverty through } \\
\text { education, training, and employment } \\
\text { Check the safety of appliances }\end{array}$ \\
\hline
\end{tabular}

examples relating to injury severity distribution of patients and investigations of accident consequences and costs to society. ${ }^{11}$

Beattie has shown the feasibility of establishing a database on childhood accidents within an accident and emergency department as a necessary step towards effective child accident prevention. ${ }^{12}$ He suggests that regular analysis and feedback of the findings to the people involved with data collection is essential. All too often studies of this type have been limited and carried out in isolation. For the information to be helpful in promoting remedial measures, it needs to be available routinely rather than on occasion through specially commissioned research.

\section{INFORMATION FROM HOSPITAL INPATIENT} RECORDS

While the emergency department is the portal of entry into hospital for seriously injured road traffic accident victims, these account for only a small proportion of patients recorded on inpatient data systems. It has been suggested that injury surveillance efforts should focus on fatal and severe injuries by using inpatient and mortality data, however such a focus would underestimate the effectiveness of remedial interventions. ${ }^{13}$

SOCIOECONOMIC AND ENVIRONMENTAL FACTORS Socioeconomic inequalities in child injury rates increased between 1981 and 1991 . Currently the child pedestrian death rate for social class $\mathrm{V}$ is almost five times that of children in social class $\mathrm{I}^{14}$ Therefore if these gradients continue, the Health of the Nation's accident target is not likely to be met for children in manual social classes.

One of the objectives set out in the government's green paper, Our Healthier $\mathrm{Na}$ tion, is to improve the health of the worst off in society and to narrow the health gap. ${ }^{15}$ The draft national contract (part of which is shown above in table 1) sets out the action required to meet a new national target to reduce accidents by at least one fifth by the year 2010 .

A research review of child pedestrian accidents by Christie for the Department of Transport observed that social class gradient is probably a feature of many types of accidental road trauma in children. ${ }^{16} \mathrm{~A}$ number of possible social and environmental factors were identified relating to overcrowded accommodation, limited play space, low car accessibility, and exposure to fast moving traffic. Direct association between such factors and the occurrence of accidents however, is not considered straightforward, it may also depend upon exposure to risk and parental attitude.
OTHER SOURCES OF ROAD SAFETY DATA

Ibrahim and Silcock, studying the accuracy of STATS 19 data, found that highway authorities devote significant resources to checking and correcting data. ${ }^{17}$ The question has been raised whether increasing the size of the database (for example by including unreported accidents) could be more cost effective than a detailed correction of errors in reported accidents.

Austin found that routine users of traffic data supplement the STATS 19 information with sources based on traffic flows and letters from the public. ${ }^{18} \mathrm{He}$ concluded that authorities should be encouraged to collect data from hospitals and primary care consultations in order to provide "new" information on unreported accidents and injuries sustained. Additionally there may be much to be learned from studying "damage only" incidents as the occurrence of injury could be considered to be a chance consequence in some situations. Road network information (perhaps from maintenance monitoring systems), insurance companies, and other agencies all have a part to play but appropriate data linkage systems need to be established.

\section{Data linkage}

Austin's work has confirmed the feasibility of using matching algorithms to provide reliable, linked databases which can be used for specific research purposes. ${ }^{19}$ Hopkin et al have reported on work forming part of a programme to produce revised costs of injuries sustained in non-fatal road accidents. ${ }^{20}$ They were able to estimate the effects of under-reporting, underrecording, and misclassification of injury. The database not only reflects outcome in terms of death or survival, but also incorporates a measure of ensuing disability.

\section{RECENT RESEARCH PROGRAMMES}

To improve the quality of data for accident prevention, studies such as the Wirral Accident Research Network ${ }^{21}$ and CRASH ${ }^{22}$ (Coordinated Research into Accidents on Salford's Highways) have been established. Hospital data (from patients attending emergency departments) have been linked with information collected by the police to provide evidence of under-reporting and inaccuracy. These studies also allow links between accident factors and injury type to be established.

The CRASH project has established an extended database of information on all road traffic accidents to children in Salford. An interim analysis of these data has been reported elsewhere. ${ }^{23}$ Preliminary findings suggest that data provided by the police and used by Salford City Council to make decisions on 
road policy are incomplete. The true proportion of injured children is actually much higher when hospital details of injury are assessed.

If under-reporting could be shown to be consistent across the city in terms of category of road user and injuries sustained, then it would probably make little difference to an accident remedial strategy. However the CRASH study has demonstrated that underreporting is not evenly represented, making simple mathematical correction inappropriate, and that more accurate information would likely change the priority order for application of resources across the city.

\section{Multiagency approach}

ROLE OF THE HEALTH PROFESSIONAL

Evidence suggests that health workers have a valuable contribution to make to the development of child accident prevention measures through their immediate contact with the public, at the political level, and as providers of social scientific data and analysis. ${ }^{24}{ }^{25}$ This is a view developed by Roberts who suggests that while transport policy is unfamiliar to most health professionals, they have an important part to play in raising the profile of child traffic accidents at a political level. ${ }^{26}$ Multiagency projects such as the CRASH programme have demonstrated the value ascribed to medical data by local authority planners.

Discussion on policy and practice must be evidence based. Health service researchers are able to use existing hospital data systems and established survey and questionnaire methods to add to the work conducted by traffic accident engineers and planners. Typical approaches focus on measuring exposure to risk, the effect of environmental factors, and the spatial distribution of accidents. Towner et al associated a relative injury risk according to journey type and relative to sex, age, and affluence. ${ }^{27}$ Roberts et al undertook a case-control study to identify and assess the contribution of a number of potentially modifiable environmental risk factors for injury of child pedestrians. ${ }^{28}$ Traffic volumes and high density on-street parking were identified as important variables.

ENVIRONMENTAL CHANGE

In almost all cases where accident prevention solutions have been shown to be effective those solutions have been ones which involve environmental change. ${ }^{24}$

A review of the impact of the introduction of 200, $20 \mathrm{mph}$ zones found an overall reduction in accidents of $60 \%,{ }^{29}$ with children as the major beneficiaries. It is recommended that 500 additional $20 \mathrm{mph}$ zones be approved by the year 2002. However, an unanswered question is whether this is the best that can be achieved. How will the 500 sites be chosen? and will the databases both for accident occurrence and consequential injury be accurate?

Much of the previous work on road traffic accidents has been based on analysing "clusters" of accidents, despite evidence that child pedestrian accidents tend to be more widely dispersed than this. ${ }^{30}$ Environmental improve-

\section{Key messages}

- Multiagency working is the most effective approach

- Hospital recording on a large scale over a long period of time is feasible and results in useful injury prevention data

- In order to be effective, the results must be disseminated quickly

ments based on traffic engineering methods designed around accident clusters do not involve the calculation of accident rates, consequently the population at risk is not considered. Kendrick has shown that areas with high accident rates may be missed using "blackspot" or cluster analyses while area wide interventions have a greater potential to reduce such accidents. ${ }^{31}$ This "area wide" approach has been adopted as important part of the government's accident reduction strategy.

\section{BEHAVIOUR MODIFICATION}

Pedestrian education has been the most commonly used strategy to prevent injury. ${ }^{24}$ While educational campaigns can substantially improve a child's knowledge about street crossing, this often does not translate into improved behaviour. Preston reviewed a large number of programmes designed to educate primary schoolchildren in the north of England and found dismal results. ${ }^{32}$ Recommendations from the British Medical Association's publication, Road Transport and Health, suggest that guidelines should be developed for involving health promotion staff and the encouragement of "Safe Routes to Schools" initiatives."

\section{COMMUNITY PARTICIPATION APPROACH}

In Scandinavia, where child accident rates are relatively low, the concept of the safe community has developed within the framework of the World Health Organisation Global Programme for Accident Prevention. ${ }^{4}$ Interventions in this mode emphasise the need for local people to control and shape the intervention from the beginning in partnership with statutory and voluntary agencies.

The Harstad injury prevention study undertaken in two cities in Norway describes a database of all hospital treated traffic injuries recorded for a period of seven and a half years. ${ }^{33}$ The data were actively used in the planning, analysis, and implementation of a community based intervention programme in one of the cities (with the other city acting as a control). Community intervention included counselling parents, items in the local media, introduction of cycle paths, and education in schools by children injured in a road traffic accident. The study showed that long term collection of road traffic accident data by a hospital in a community of 22000 people is feasible, resulting in a database superior to the police system for accident analysis and injury prevention planning. A marked reduction in accidents was seen across the city where intervention was introduced when compared with the control city. 


\section{Conclusion}

Responsibility for developing and implementing injury control strategies lies with many organisations, across a wide variety of sectors. Government, both national and local, has a key role, yet more comprehensive data collection techniques are required if local authorities are to be supplied with information which accurately reflects the problems they need to address. The European Commission has also launched an ambitious programme to promote road safety within the European Union. The commission has asked member states and all decision makers to take a systematic look at the cost of road accidents when deciding whether or not to invest in or take regulatory measures in favour of road safety.

This review has identified the value of bringing together workers from different agencies who all have a primary interest in road safety. Investigation of child traffic accidents in particular will benefit from an integrated approach. This should include social, traffic, and environmental factors and is likely to lead to a more equitable distribution of limited finances, with a more focused health gain. Current data sources may be flawed in isolation but, with appropriate linkage mechanisms, can be combined effectively to enhance their value.

1 British Medical Association. Road transport and health. London: BMJ Publishing Group, 1997.

2 Roberts I, Campbell F, Hollis S, et al. Reducing acciden death rates in children and young adults: the contribution of hospital care. $B M \Im$ 1996;313:1239-41.

3 Jarvis S, Towner E, Walsh S. Accidents. In: Botting B, ed. The health of our children. London: HMSO, 1995.

4 Popay J, Young A. Reducing accidental death and injury in children. A report produced for North West Regiona children. A report produced for North West Regional Health Authority Public Health Workin

5 Ward H. Preventing road accidents in children: the role of the Ward H. Preventing road accidents in children: the role

6 Child Accident Prevention Trust. An integrated approach to road safety. London: Child Accident Prevention Trust, 1991.

7 Raffle PAB. Accident prevention. I R Soc Med 1990;83:67981.

8 James HF. Under-reporting of road traffic accidents. Traffic Engineering and Control 1991;32:574-80.

9 Walsh SSM, Jarvis SN. Measuring the frequency of "severe" accidental injury in childhood. $\mathcal{f}$ Epidemiol Community Health 1992;46:26-32.

10 Yates DW. Scoring systems for trauma. BMF 1990;301: $1090-4$.

11 Hopkin JM. Enhancing police road accident data with information from other sources: the role of hospital data. Fourth European workshop on recent developments in road safety. Crowthorne, Berkshire: Transport and Road Research Laboratory, 1991.
12 Beattie TF. An accident and emergency based child accident surveillance system: is it possible? $\mathcal{F}$ Accid Emerg Med 1996;13:116-18.

13 Weiss HB, Foriuoh SN, Coben JH, et al. The need for emergency department data in highway safety management systems. Accid Anal Prev 1995;27:621.

14 Roberts I, Power C. Does the decline in child injury mortality vary by social class? $B M F$ 1996;313:784-6.

15 Secretary of State for Health. Our healthier nation. A contract for health. London: The Stationery Office, 1998.

16 Christie N. The high risk child pedestrian: socio-economic and environmental factors in their accidents. TRL project report 117. Crowthorne, Berkshire: Transport Research Laboratory, 1995.

17 Ibrahim K, Silcock DT. The accuracy of accident data. Traffic Engineering and Control 1992;33:492-6.

18 Austin K. The collection and use of additional sources of road safety data in highway authorities. Traffic Engineering and Control 1993;34:540-3.

19 Austin K. A linked police and hospital road accident database for Humberside. Traffic Engineering and Control 1992;33:674-8.

20 Hopkin JM, Murray, PA, Pitcher M, et al. Police and hospital recording of non-fatal road accident casualties: a study in Greater Manchester. Research report. Crowthorne, Berkshire: Transport Research Laboratory, 1992.

21 Wirral Accident Research Network. Bridging the gap in accident statistics. Report compiled by Norbury P, Atherton J, Rees $D$ on behalf of the Wirral Accident Research Network, 1996.

22 Claxton H. Reducing accidents to children in Salford; a multi-disciplinary approach. Proceedings of the 3rd national conference of the Institute of Traffic Accident Investigators. Telford, 14-16 November 1997. AFL Deeson Partnership, Kent, 1997: 111-17.

23 Henson R, Cooper S. Extending the quality and quantity of traffic accident related data. Proceedings of the road safety in Europe conference. Birmingham, 9-11 September 1996. Europe conference. Birmingham, 9-11 September 1996.
Stockholm: Swedish National Road and Transport ReStockholm: Swedish

24 Sibert JR. Accidents to children: the doctor's role. Education or environmental change? Arch Dis Child 1991 66:890-3.

25 Christophersen ER. Accident prevention in primary care. Pediatr Clin North Am 1986;33:933.

26 Roberts I. Injuries to child pedestrians. BMF 1995;310:413 14.

27 Towner EML, Jarvis SN, Walsh SSM, et al. Measuring exposure to injury risk in school children aged 11-14. BMF 1994;308:449-52.

28 Roberts I, Norton R, Jackson R, et al. Effect of environmental factors on risk of injury of child pedestrians by motor vehicles: a case-control study. BMf 1995;310:91-4.

29 Transport Research Laboratory. Review of traffic calming schemes in $20 \mathrm{mph}$ zones. Report 215. Crowthorne Bchemes in 20 mph zones. Report 215. Crow

30 Lawson SD. Accidents to young pedestrians: distributions, circumstances, consequences and scope for counter measures. AA Foundation for Road Safety Research and Birmingham City Council. Basingstoke: AA Foundation for Road Safety Research, 1990.

31 Kendrick D. Prevention of pedestrian accidents. Arch Dis Child 1993;68:669-72.

32 Preston B. Child pedestrian casualties with special reference to casualties on the journey to or from school in Manchester and Salford, England. Accid Anal Prev 1989;21:291301 .

33 Ytterstad B, Wasmuth HH. The Harstad injury prevention study: evaluation of hospital based injury recording and community based intervention for traffic injury prevention. Accid Anal Prev 1995;27:111-23. 